\title{
Ambient lighting, use of outdoor spaces and perceptions of public safety: evidence from a survey experiment
}

\author{
Jacob Kaplan ${ }^{1} \cdot$ Aaron Chalfin ${ }^{2}$
}

Accepted: 24 March 2021 / Published online: 11 April 2021

(c) The Author(s), under exclusive licence to Springer Nature Limited 2021

\begin{abstract}
Observational evidence suggests that better ambient lighting leads people to feel safer when spending time outdoors in their community. We subject this finding to greater scrutiny and elaborate on the extent to which improvements in street lighting affect routine activities during nighttime hours. We report evidence from a survey experiment that examines individuals' perceptions of safety under two different intensities of nighttime ambient lighting. Brighter street lighting leads individuals to feel safer and over half of survey respondents are willing to pay an additional $\$ 400$ per year in taxes in order to finance a hypothetical program which would replace dim yellow street lights with brighter LED lights. However, poor lighting does not change people's willingness to spend time outdoors or to engage in behaviors which mitigate risk. Results suggest that street lighting is a means through which policymakers can both control crime and improve community well-being.
\end{abstract}

Keywords Place-based crime control $\cdot$ Street lighting $\cdot$ Perceived safety $\cdot$ Survey experiment

\section{Introduction}

Street lights are widely thought to be an effective tool in reducing crime and have therefore become a ubiquitous type of investment in environmental design (Painter and Farrington 1999b; Farrington and Welsh 2002; Welsh and Farrington 2008) and a key part of many crime prevention through environmental design (CPTED) efforts (Robinson 2013). The available evidence on street lighting suggests that its impact on public safety is promising, reducing crime by, on average, 20\% (Welsh and Farrington 2008) and perhaps by as much as $40 \%$ if lighting is deployed in order

Aaron Chalfin

achalfin@sas.upenn.edu

1 Princeton University, Princeton, USA

2 Department of Criminology, University of Pennsylvania, 558 McNeil Building, Philadelphia, USA 
to maximize its salience to community residents (Chalfin et al. 2020). Findings are especially large for common street crimes like robbery (Doleac and Sanders 2015; Domínguez and Asahi 2019) and motor vehicle theft (Davies and Farrington 2018) and possibly even homicide in a developing country setting (Arvate et al. 2018).

Darkness is thought to generate a sense of insecurity because it decreases visibility and recognition at a distance, creating a limitless source of blindspots, shadows and potential places of entrapment (Painter 1996; Haans and De Kort 2012). In contrast with the concentration of police personnel at crime hot spots which tends not to reduce fear (Weisburd et al. 2011; Ratcliffe et al. 2015), research in criminology, public health and urban planning suggests that improvements in lighting are welcomed by residents (Atkins et al. 1991; Steinbach et al. 2015; Struyf 2020) and modestly improve perceptions of community safety

(Tien et al. 1977; Vrij and Winkel 1991; Herbert and Davidson 1994; Painter 1996; Calvillo Cortés and Falcón Morales 2016; Crosby and Hermens 2019). However, the majority of the evidence is more than 25 years old and was generated during a period of time when national crime rates in the United States and the United Kingdom, the setting for the lion's share of the research, were near their global maximum. Estimates are also largely derived from evaluations which either do not employ a comparison group (Herbert and Davidson 1994; Painter 1996) or quasiexperimental evaluations which compare changes in perceived safety in a single community exposed to enhanced lighting to a community which did not receive enhanced lighting (Atkins et al. 1991; Painter and Farrington 1999b). Even when an untreated community is available, such comparisons can be problematic as community crime and perceived safety tend to fluctuate for many reasons (e.g., a salient but rare event such as a shooting or media coverage of crime). This type of unobserved heterogeneity may, in turn, lead to biased estimates of the impact of newly installed lighting. While research that studies many communities which are treated at different times can net out this variation through the use of fixed effects, in a single community, the assumption that the timing of lighting upgrades is conditionally random can be difficult to defend.

Appreciating how ambient lighting affects perceptions of safety is of critical importance to understanding the scalability of public investments in street lighting as a crime control strategy for several reasons. First, perceived safety is an important outcome in its own right. While crime is typically the primary outcome of interest in research on place-based crime prevention programs, to the extent that an intervention simply makes people feel safer, it can substantially improve the welfare of a community (Johnson et al. 2009; Struyf 2020). Second, perceptions of safety are a major driver of the use of public space and active and healthy living for residents in disadvantaged communities (Painter 1996; Roman and Chalfin 2008; Roman et al. 2009; Esteban-Cornejo et al. 2016; Patch et al. 2019). Even in national samples, research reports that many individuals never leave home after it is dark due to concerns regarding their safety (Kershaw et al. 2001; Cozens et al. 2003). Third, the response of potential victims to a public safety intervention is a key mediator of an intervention's efficacy and, as such, evidence on victim behavior is needed to contextualize effects observed in the large and growing empirical literature that studies the effect of ambient lighting on crime (Welsh and Farrington 2008; Doleac and 
Sanders 2015; Arvate et al. 2018; Davies and Farrington 2018; Chalfin et al. 2020). In particular, to the extent that lighting makes individuals feel safer and thus draws them outdoors during nighttime hours, the number of available crime victims might increase, an effect which would tend to counteract the principal goal of municipal investments in lighting (Cozens et al. 2005; Lorenc et al. 2012). Given the age and nature of the available evidence, we continue to have a very limited understanding of the extent to which potential victims change their routine activities in response to better nighttime lighting (Welsh and Farrington 2008; Struyf 2020). ${ }^{1}$

This research provides a critical update to prior quasi-experimental and experimental research on ambient lighting and perceptions of public safety. Drawing on an early survey experiment by Vrij and Winkel (1991) as inspiration, we randomly assign respondents to a treatment condition in which they are shown a photo of a block with enhanced lighting and a control condition in which they are shown a photo of a block in which "business-as-usual" lighting is used. ${ }^{2}$ We ask respondents to reveal the extent to which they would feel safe walking alone at night on the block that is pictured in the photo that they were randomly assigned to view. ${ }^{3}$

To ensure that our survey is closely connected to a policy-relevant counterfactual (Nagin and Sampson 2019), the photos we use derive from an actual municipal program that upgraded the brightness of existing street lighting - using lightemitting diode (LED) lights-in Chicago. ${ }^{4}$ A number of large cities in the United States are replacing all or most of their current street lights with ones that have LED bulbs which are generally far brighter and whose advocates have claimed that they will drastically improve public safety (Gregory 2013; Maddox 2016; Shueh 2017; Trickey 2017; Liberatore 2018). This research examines support for these types of efforts, and particularly how much community residents are willing to pay to make these improvements. Using a contingent valuation survey, we ask respondents about their willingness to pay for improvements in municipal lighting. To our knowledge the only other research that estimates the willingness of taxpayers to fund investments in municipal street lighting is that of Willis et al. (2005) who use contingent valuation in a survey sample from the United Kingdom.

\footnotetext{
${ }^{1}$ Not limited to street lighting, this issue has broad applicability to a great many place-based crime control strategies including community greening (Branas et al. 2011; Garvin et al. 2013a, b; Kondo et al. 2016), remediating blighted land (Branas et al. 2012; Garvin et al. 2013a, b; Branas et al. 2018; Moyer et al. 2019) and hot spots policing strategies (Sherman and Weisburd 1995; Weisburd and Green 1995; Weisburd et al. 2009; Braga and Weisburd 2010; Braga et al. 2014).

${ }^{2}$ This is the only survey experiment in the extant literature. In Vrij and Winkel (1991), researchers brought subjects to an area in Enkhuizen, a city in the Netherlands, on two different evenings. On one evening, business-as-usual street lighting was provided. On a second evening, the lighting was enhanced by a factor of five. Subjects reported feeling significantly safer under the brighter lighting condition.

${ }^{3}$ Vignette studies have been used in recent research on the effect of ambient lighting on feelings of safety. However, survey respondents have not been randomized to treatment and control conditions. See e.g., Calvillo Cort'es and Falco'n Morales (2016).

${ }^{4}$ Chicago is one of many cities including, among others, NYC and Los Angeles that is investing heavily in LED upgrades. For a review of the cost-effectiveness of LED lighting, see Cacciatore et al. (2017).
} 


\section{Street lighting, fear of crime, and use of public space}

While outdoor lighting has been used in one form or another for millennia (Ellis 2007), due to the numerous ways in which both potential offenders and potential victims may be responsive to lighting, there continues to be uncertainty about the precise mechanisms through which lighting affects crime. With respect to the responsiveness of potential offenders, the presence of ambient lighting may increase the perceived certainty of apprehension for a given crime, thus deterring criminal activity (Becker 1968; Akers 1990). As noted in Chalfin et al. (2021), this might be because a police officer can detect criminal activity more easily in an area that is well lit, because lighting increases the probability of a witness (Jacobs 1961; Painter and Farrington 1999a, b) or because lighting increases the effectiveness of complimentary technology like surveillance cameras (Piza et al. 2015). Relatedly, to the extent that lighting increases the actual probability of apprehension, it may decrease crime by increasing the rate at which offenders are incapacitated by arrest and subsequent incarceration. ${ }^{5}$ Greater visibility also might empower potential offenders by reducing their search costs, enabling them to locate more vulnerable victims or lucrative criminal opportunities (Ayres and Levitt 1998; Welsh and Farrington 2008; Chalfin et al. 2021). ${ }^{6}$

At the same time, investments in lighting may also generate behavioral responses from potential victims. In particular, lighting may change how public space is used during nighttime hours, thus giving rise to two potentially countervailing effects (Painter 1994, 1996; Chalfin et al. 2020). On the one hand, more outdoor activity tends to create a greater pool of potential witnesses (Cozens and Hillier 2012; Cozens and Davies 2013) thus changing the costs of crime by increasing the certainty of apprehension (Carr and Doleac 2018). On the other hand, more human activity in an area mechanically increases the number of potential victims and therefore increases the number of criminal opportunities. While the majority of prior research suggests that the addition of lighting leads to public safety benefits, the effect of ambient lighting on crime remains theoretically ambiguous and will depend, to a large extent on the degree to which both offenders-and victims - are "coupled to place" (Weisburd et al. 2014).

Independent of its effect on actual safety, investments in outdoor lighting can also affect the extent to which community members feel safe spending time outdoors at night and the extent to which they use public spaces after dark. While

\footnotetext{
${ }^{5}$ Prior research has also emphasized the importance of lighting as an investment in neighborhood conditions that may strengthen community social cohesion (Skogan 1990) and therefore has suggested that lighting can influence public safety through channels that do not directly affect an offender's proximal risk of detection (Welsh and Farrington 2008; Chalfin et al. 2021). For example, an improvement in the physical environment of a neighborhood, such as the installation of new street lights, may serve as a cue that an area is cared for and that criminal behaviors violate community norms (Sampson et al. 1997). Under this theory, street lighting might impact crime by signaling that the residents-and the local government—care for the area and would respond more harshly to crimes that occur there than in another area.

${ }^{6}$ These impacts may be further mediated by the extent to which the composition of individuals who spend time outdoors changes (Cohen and Felson 1979).
} 
these ideas have been discussed at length in the recent academic literature (Painter 1996; Welsh and Farrington 2008), the essentials of this insight have been recognized for at least several hundred years. Indeed, one of the primary motivations for expansion of outdoor lighting in 17th century Europe was to allow more people to use outdoor areas at night without fear for their personal safety (Schivelbusch 1987).

As noted by Painter (1996), darkness reduces visibility and recognition at a distance, thus creating a limitless source of blindspots, shadows and potential places of entrapment. This leads to a number of specific sources of fear. First, darkness makes it more difficult for potential victims to identify and mitigate their risk of a crime by taking precautionary actions such as crossing the street upon seeing a suspicious person or avoiding an area in which suspicious people have gathered (Stanko 1995; Pain et al. 2006). Given that people tend to overstate the risk of costly but rare events (Slovic et al. 1982; Kahneman 2011), to the extent that individuals tend to overestimate their risk of crime (Jeffords 1983; Quillian and Pager 2001), darkness may compound existing fears. Second, to the extent that pedestrians tend to avoid poorly-lit areas, dark streets may have fewer capable guardians meaning that there may be no one who is available to come to a victim's aid in the event of an attempted crime (Sherman et al. 1989; Painter 1996). Finally, potential victims tend to consider the perspective of an offender, positing that offenders may feel most comfortable in dark areas where there is a reduced probability of being interrupted, recognized and apprehended. As such, they worry, perhaps correctly, that motivated offenders may be more commonly found where ambient lighting is poor or unavailable (Painter 1996).

Given the theoretical link between darkness and fear, it is perhaps unsurprising that prior research has found that individuals - and particularly women, who report higher fear of crime than men (Stanko 1995; Roman and Chalfin 2008)feel safer in areas that are brightly lit (Painter 1994, 1996; Chalfin et al. 2020). As such, it is possible that individuals may reduce outdoor discretionary activities when the perceived cost of those activities is higher. Though research on the direct impact of lighting on use of public space is limited (Markvica et al. 2019), a related literature establishes strong associations between fear of crime and the use of public space (Roman and Chalfin 2008; Roman et al. 2009; Shinew et al. 2013; Stodolska et al. 2013). As such, to the extent that better lighting reduces fear, it is possible that it will also increase outdoor activity during nighttime hours. At the same time, many nighttime activities (e.g., employment or childcare obligations) are not discretionary and other activities, while discretionary, might be associated with considerable benefits which are large enough to outweigh the costs imposed by increased fear. Ultimately the extent to which investments in lighting change the use of public space - and the degree to which community residents are willing to pay for increased lighting in the first place-are empirical questions. We test each of these questions using a survey experiment in which survey respondents are randomly primed to think about public safety under a different lighting condition. 


\section{Survey experiment}

\section{Background}

We study the effect of ambient lighting on perceptions of public safety using a survey experiment, a methodology which randomizes research participants to participate in either a treatment or a control version of a survey. The virtue of survey experiments is that they allow researchers to generate "gold standard" social science evidence at low cost, credibly allowing researchers to generate causal inferences which would have been difficult to defend based on observational research. This feature of survey experiments is especially welcome when an intervention of interest is difficult to randomize or provide in sufficient numbers to study using a rigorous research design, both of which have been noted as critical limitations to studying the effect of lighting on crime (Farrington and Welsh 2002; Davies and Farrington 2018; Chalfin et al. 2020). Likewise, survey experiments are particularly useful when key outcomes are attitudinal or are poorly measured using administrative data. Given their usefulness in many different contexts, survey experiments have a rich tradition in experimental economics (Chaudhuri 2011; Cruces et al. 2013; Kuziemko et al. 2015) in public opinion research in political science (Harbridge and Malhotra 2011; Samuels and Zucco Jr 2014) and have a limited but growing presence in experimental criminology (Herzog 2003; Groff et al. 2005; Berryessa et al. 2016; Buckley et al. 2016; Liao et al. 2016; Berryessa 2017 2018; Dunbar and Kubrin 2018; Headley et al. 2020; Block et al. 2020; Dunbar 2020; Kaplan et al. 2020; Shi 2020).

The key drawback of survey experiments-or any experiment in which key outcomes are measured using survey data-is that survey responses may suffer from a number of measurement problems which derive from the relative willingness or ability of respondents to report their experiences accurately to researchers. In this context, an important drawback of the survey experiment approach is that respondents are asked about a hypothetical scenario involving improved street lighting rather than an experience that they have actually had in the real world. As a result, there is some inherent difficulty in mapping survey responses on to actual preferences as respondents may not "do what they say" (Kroes and Sheldon 1988). Concerns regarding the validity of survey data generally have been noted at length in every social science discipline. Nevertheless, owing to its ability to address hard-to-measure outcomes, survey data continues to be a ubiquitous and possibly even the dominant source of evidence in criminological research (Kleck et al. 2006). Indeed, survey research remains a critical and sometimes the primary source of what we know about the prevalence of crime (Baumer and Lauritsen 2010; Gutierrez and Kirk 2017), the deterrence value of sanctions (Pogarsky et al. 2005; Apel et al. 2009; Nagin et al. 2013) and life course criminology (Farrington 2003; Apel et al. 2009) among many other core literatures.

A second set of concerns has to do with the representativeness of the respondent survey pool, especially degree to which research participants may be 
"professional research subjects" (Chandler et al. 2014) or the broad discretion that participants have to opt into a given research study. While survey experiments face legitimate challenges to their generalizability, recent research reports a reassuring degree of agreement between survey samples obtained from validated samples of the general population and convenience samples, including those obtained from Amazon Mechanical Turk, the source of the survey sample we analyze in this paper (Goodman et al. 2013; Mullinix et al. 2015; Coppock 2019). As reported by Goodman et al. (2013), Mechanical Turk participants have attitudes about money that are different from a community sample's attitudes and are less extroverted and have lower self-esteem than other participants, presenting challenges for some research domains. However, they report that despite these differences, Mechanical Turk participants produce reliable results consistent with standard decision-making biases: they are present biased, risk-averse for gains, risk-seeking for losses, show delay/expedite asymmetries, and show the certainty effect-with almost no significant differences in effect sizes from other samples.

While there is now considerable optimism that convenience samples derived from Amazon Mechanical Turk and national surveys typically tend to produce similar findings, we have taken several steps in order to assess the extent to which our results are sensitive to sample selection. First, we report estimates using raw data as well as data which have been re-weighted to resemble the population of U.S. adults with respect to age, gender, and race. Second, we report estimates separately by demographic subgroup and test whether there are important differences between respondents who have recently been the victim of a crime and those who have not. Finally, we note that our data were obtained during the COVID-19 pandemic which naturally raises questions about the degree to which respondents are primed to think about public safety as opposed to the disruption to ordinary living brought about by the pandemic. While we cannot address these concerns completely, we are able to compare our survey responses with a pilot survey which we administered in February 2020 prior to the beginning of the pandemic. As we report in Section 5.3 "External validity", results are extremely similar thus providing some assurance that estimates have not been contaminated by the pandemic.

\section{Survey instrument and measures}

We sought to obtain a sample of $N=1000$ survey respondents using Amazon's Mechanical Turk website, a crowd-sourced marketplace and online survey platform in which "workers" can be contracted to perform tasks-including completing a survey - by a requester. ${ }^{7}$ Mechanical Turk has become a mainstay of research in psychology, political science and experimental economics. While MTurk, to date, has been not been as popular in criminological research (Ozkan 2019), recent research has used Mechanical Turk to identify demographic heterogeneity in deterrence effects (Fine and Van Rooij 2017) knowledge about "elite deviance" (Michel et al.

\footnotetext{
7 This research was approved by our university's Institutional Review Board in February 2020. The name of the university is, for the time being, redacted in order to comply with blinded peer review.
} 
2015), and opinions on forensic evidence (Kaplan et al. 2020). We restrict respondents to those who live in the United States. All responses were collected on Friday July 3, 2020. In keeping with prior criminal justice research, participants were paid 25 cents for their participation in our 2-3 min survey.

In order to assess the degree to which perceptions of safety are sensitive to better lighting, we show respondents one of two photographs of the same Chicago street, taken during nighttime hours. Photos used in the experiment are presented in Fig. 1. The first photo depicts the street as has been lit using standard "business-as-usual" municipal street lighting - this is the control condition. The second photo depicts the street after the city of Chicago upgraded the lighting on this street, by installing brighter LED lights. Notably these photos reflect actual street conditions and the change in lighting brought about by a municipal lighting intervention, thus enhancing the policy relevance of the exercise. Upon randomizing respondents to see one of the two photos, we next asked a series of questions about perceptions of safety and a respondent's willingness to use public space at night. A complete copy of the survey instrument can be found in Appendix C.

\section{Fear of crime and use of public space}

After reviewing a randomly assigned version of the photo, respondents were asked three questions intended to elicit their perceptions of public safety and their willingness to spend time outside at night. ${ }^{8}$ In the spirit of prior survey research by Vrij and Winkel (1991), respondents are first asked to indicate the degree to which they "would feel safe walking alone at night on a street that looks like [the street in the photo]." Respondents were directed to answer on a five-point Likert-scale ranging from Strongly Agree (1) to Strongly Disagree (5). A neutral response of Neither agree nor disagree was also provided.

Next, we ask two questions designed to assess a respondent's willingness to use public spaces at night under different intensities of street lighting. We begin with a short vignette in which the respondent is invited to a friend's house at night after the sun has gone down. The respondent is told that his/her friend lives a short distance (five blocks) away but that he/she is unable to drive to this friend's home because of car troubles. The complete vignette text is below:

Imagine that you live on the street on which this photo was taken. A close friend who lives five blocks away from you invites you to hang out at 9:00pm after it is already dark outside. Your car is being repaired so driving is not an option. Thinking about any concerns you might have about your safety, which of the following best describes what you will do?

\footnotetext{
${ }^{8}$ In all questions, respondents were prompted to "please think about the time period prior to the COVID-19 pandemic."
} 


\section{A Control Condition ("Business-as-Usual" Lighting)}

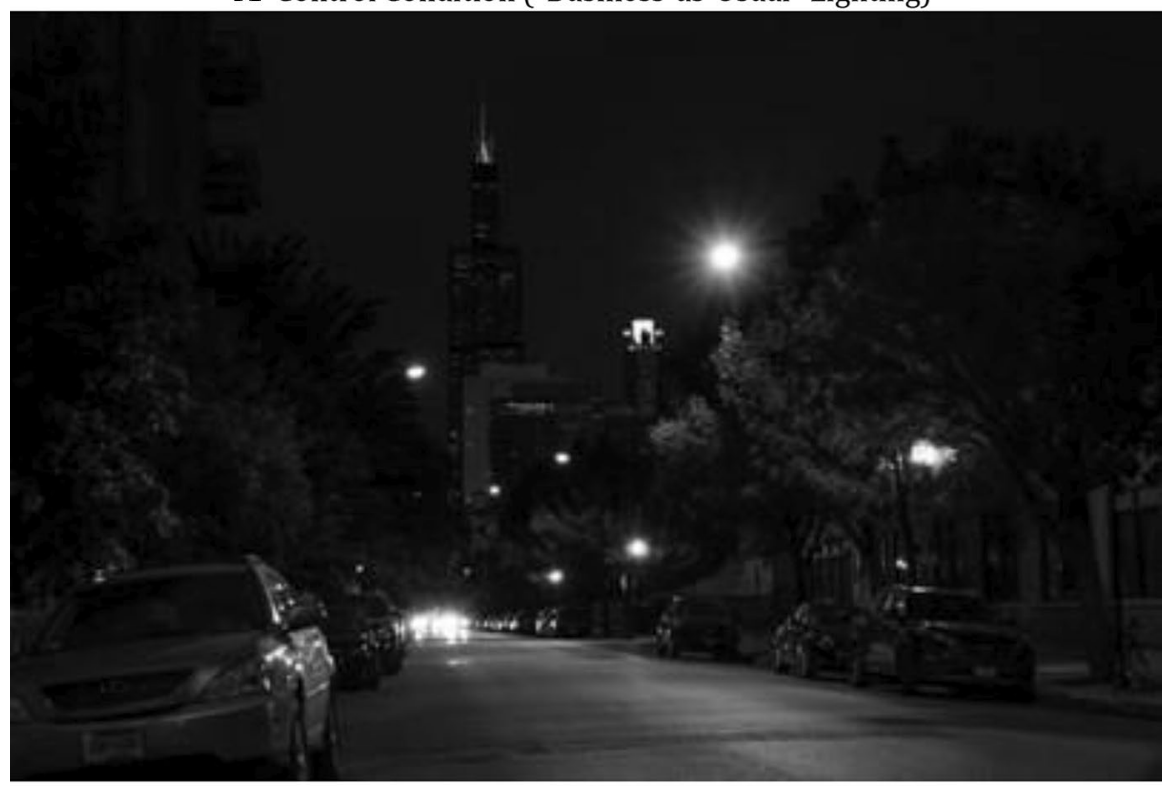

B Treatment Condition (Upgraded LED Lighting)

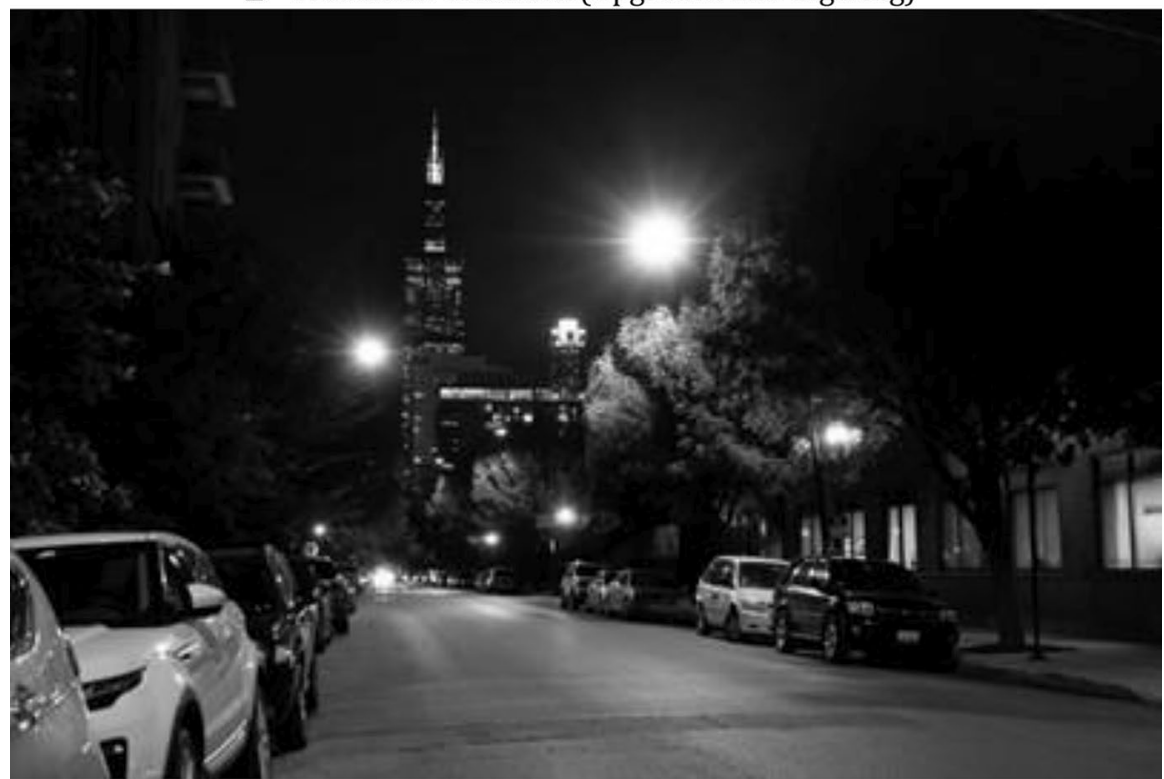

Fig. 1 Control and treatment photos utilized in the survey experiment 
Respondents were asked to indicate what they would do in this situation, by selecting one of four multiple choice answers. ${ }^{9}$

(1) Walk to your friend's house

(2) Take a taxi or a car service (e.g. Uber, Lyft)

(3) Choose to stay home-I would be worried about my safety

(4) Choose to stay home-I prefer to stay at home for other reasons

By providing respondents with the choice to remain home for reasons having nothing to do with perceived safety, we ensure that we are not creating a false choice for respondents who are less social or who prefer to remain at home for another reason.

Finally, respondents are asked to how many nights per week they would likely spend outside their home given the amount of outdoor lighting in the photo they were shown. The purpose of this question to gain a more global perspective on how much time at risk changes in response to better lighting. In particular, we use this question as a proxy for victimization risk in terms of man-hours spent outdoors at night. While the question does not allow us to obtain granular information about exactly what types of activities a respondent plans to engage in while outdoors, it does give us a sense for the extent to which overall time spent outdoors during nighttime hours may be sensitive to street lighting.

\section{Willingness-to-pay for improved lighting}

Next, we seek to understand the value that community residents place on enhanced lighting, a task which is complicated by the fact that, unlike goods and services that are exchanged on the free market, street lighting is both non-rivalrous and nonexcludable. By non-rivalrous, we refer to the idea that one consumer's enjoyment of additional street lighting does not prevent another consumer from enjoying those same benefits. By non-excludable, we refer to the concept that a consumer who purchases street lighting has no means of excluding others from enjoying the same benefits that he or she enjoys. Street lighting is, therefore, a "public good" (Samuelson 1954) which is purchased and maintained by municipal government rather than by individual consumers. While the price of a private good like an apple is determined by the cost of growing, packaging, shipping and selling the apple as well as by consumer demand for apples, the market for street lighting reflects the valuation of lighting by city planners and not necessarily the value of lighting to community residents (Chalfin 2015).

Recognizing that public goods like street lighting — or public safety more generally - are difficult but important to value, economists have developed a host of techniques to do so. One of the primary tools that is used to value non-market goods is contingent valuation, a survey-based valuation technique used to elicit individuals'

\footnotetext{
9 The answers were presented in a random order to avoid priming a respondent based on the ordering of the answer choices.
} 
willingness to pay for a particular good or service (Cameron and James 1987). Developed initially by environmental economists to value goods like clean air and unpolluted water, contingent valuation has, in recent years, become a staple methodology to value the benefits of public safety (Ludwig and Cook 2001; Cohen et al. 2004; Nagin et al. 2006; Cohen and Piquero 2009). We use contingent valuation to assess the degree to which respondents are willing to incur higher taxes in order to support enhanced municipal lighting. Typically, contingent valuation survey questions ask individuals how much money they would be willing to pay for an increase in some non-market good (such as safety), or, alternatively, how much money they would need to be fully compensated for a decrease in the quantity of a non-market good (Roman et al. 2010). In our context, we measure survey respondents' willingness to pay for a specific increase in the amount of nighttime ambient lighting.

One of the chief difficulties in using contingent valuation is that it elicits respondents stated rather than revealed preferences. As such, there are concerns about whether respondents will answer questions honestly and realistically, given that they face an implicit budget constraint. Given the importance of valuing nonmarket goods and the ubiquity of contingent valuation, a large methodological literature in economics as well as in other social sciences fields has arisen to counsel researchers on best practice in fielding contingent valuation surveys. Following a series of recommendations made to the National Oceanic and Atmospheric Administration by a panel that included several Nobel Prize winning economists, researchers typically eschew open-ended questions in favor of questions that ask respondents to pick a number from a list of choices (Arrow et al. 1993). While there are a variety of approaches have been used in the literature, it is particularly common for researchers to use a series of iterative binary choice questions asking respondents whether they would be willing to pay a particular amount of money for a given social program. Respondents are either then asked follow-up questions about different values in order to further narrow down their preferences or a single data point is used for each respondent.

In this research, we follow one such approach used in prior criminal justice research by Cohen et al. (2004) and Nagin et al. (2006), among others. Respondents are asked whether they would be willing to pay $k$ dollars for a government program that improves municipal lighting in their community where $k$ is randomly selected from the following list of values: $\$ 25, \$ 50, \$ 75, \$ 100, \$ 200, \$ 400$. We randomize the value of $k$ that is shown to each survey respondent thus guaranteeing that $k$ is uncorrelated with respondent characteristics. We can then estimate the share of respondents who are willing to pay at least $\$ k$ for improved street lighting for each of the values of $k$ used in the survey. We use this design to estimate a quasi-demand curve plotting the share of respondents willing to support a lighting program against the universe of values of $k$. To anchor respondents to a standardized and, above all, realistic lighting program, we show them both the pre-LED and post-LED photo of the Chicago street segment they were asked to respond to earlier in the survey. Respondents were asked to indicate their willingness to pay for a program that will bring the amount of lighting from the pre-LED condition to the post-LED condition. 


\section{Respondent demographics}

Finally, we collect basic demographic information from our respondents. This information includes a respondent's age (in years), gender and self-reported race/ ethnicity (American Indian or Alaska Native, Asian/Pacific Islander, Black, White, Hispanic/Latino, Other). ${ }^{10}$ Next, we asked each respondent to indicate his or her highest level of completed education and 2019 household income. ${ }^{11}$ We also ask each respondent whether he or she has been the victim of a crime in the prior twelve months and, using a Likert scale, the degree to which he or she feels safe walking around their own neighborhood after dark. Demographic information was collected at the end of the survey in order to guard against inappropriately priming respondents to answer questions on the basis of their demographic characteristics. Finally, the survey included an "attention check" question which allows us to purge the data of responses from individuals who answered survey questions without reading or comprehending them. In particular, we ask respondents about the nature of the photo they were shown at the beginning of the survey. The choices were: a city street, a farm, a classroom and the inside of a prison. We exclude 49 out of 1000 respondents who failed to indicate that the photo was of a city street. ${ }^{12}$ We excluded two additional respondents who reported their age to be under 18.

\section{Empirical methods}

In this section we describe the empirical models which we use to estimate the effect of improved municipal street lighting on respondent perceptions. Upon being randomized to view either the treatment or the control version of the photo, respondents were asked three questions. First, respondents were asked to indicate their agreement (on a five-point Likert scale) as to whether they would feel safe being outdoors at night. Second, respondents were asked to describe what actions they would take if offered the opportunity to spend time at a friend's home after dark- the choices were: (1) walk to friend's house, (2) take a taxi, (3) choose to stay home due to worries about safety and (4) choose to stay home for other reasons. Finally, respondents were asked how many nights, in a typical week, that they would spend outside their home given the amount of lighting in the photo shown.

From these survey questions we construct four primary dependent measures, three of which are binary and one of which is continuous:

\footnotetext{
${ }_{10}$ Respondents were asked to indicate as many race/ethnicity groups as they desired.

11 Education categories include: < high school, high school graduate, Some college, 2-year college degree, 4 year college degree, professional degree, master's degree and doctoral degree. Income categories include: $<\$ 20,000, \$ 20,000-\$ 39,999, \$ 40,000-\$ 59,999, \$ 60,000-\$ 79,999, \$ 80,000-\$ 99,999$ and > $\$ 100,000$. We directed respondents to think about their household income in 2019 to avoid the confounding effects on incomes that are due to the COVID-19 pandemic.

12 An equal number of treatment and control group individuals failed the attention check question. Exclusion of these observations does not appreciably change the results.
} 
- Respondent feels Unsafe: 1 if respondent disagreed or strongly disagreed that they feel safe; 0 if else

- Vignette study - Respondent would stay home due to worries about safety: 1 if yes, 0 if no

- Vignette study-Respondent would either stay home due to worries about safety or would take a taxi/rideshare: 1 if yes, 0 if no

- Number of nights respondent would spend outdoors each week

We focus on binary measures because they are clear and simple to interpret. However, we also preserve the ordinal information contained within the original variables and re-estimate models using ordinal and multinomial regressions. These estimates are substantively similar to estimates derived from the binary outcome models constructed above.

We begin by running a series of $t$-tests which test for mean differences in the proportion of "successes" between respondents in the treatment and control conditions. These tests make no functional form assumptions and, as such, constitute "pure" measures of the average treatment effect of the intervention. To generate our preferred estimates, we regress a given outcome, $Y_{i}$, on a binary treatment indicator, $D_{i}$, conditioning on a vector of respondent characteristics, $X_{i}$, which are included to improve precision and guard against finite sample bias due to imperfect randomization (Angrist and Pischke 2008; Imbens 2010). In practice, the estimates are insensitive to the inclusion of control variables. Covariates included in $X$ are a respondent's age, race, gender, completed education level, income group, as well as an indicator for whether a respondent has been the victim of a crime in the past 12 months and the extent to which a victim feels safe in general walking around his or her own neighborhood. In all models, we cluster standard errors by age-race-gender-treatment condition groups to allow for within-group dependence in regression errors.

To simplify the interpretation of estimated treatment effects, our primary models-including those for binary outcomes - are estimated via ordinary least squares regression. These models provide the best linear approximation to the true treatment effect. ${ }^{13}$ Finally, we test for treatment effect heterogeneity by age, gender, race and prior victimization by interacting, in separate models, each characteristic with the treatment indicator. In order to guard against false rejections due to multiple hypothesis testing, we test for heterogeneity with respect to only a subset of theoretically important predictors.

\footnotetext{
13 We provide estimates using logistic and probit regressions in an auxiliary analysis-estimates are substantively similar across all three modeling approaches. We also present point estimates from weighted least squares models in which we re-weight the data to resemble the U.S. population with respect to age, race and gender in an auxiliary analysis. The weight for each age-race-gender group, $W_{j}=c_{j} / s_{j}$ where $c_{j}$ and $s_{j}$ are the group's share of individuals in U.S. Census data and our survey data, respectively.
} 
Table 1 Summary statistics

Treatment (upgraded LED lighting)
Control ('business- $p$-value as-usual' lighting)

(a) Panel A: demographic variables

\begin{tabular}{|c|c|c|c|}
\hline Age & $36.710(12.353)$ & $36.455(11.885)$ & 0.746 \\
\hline Male & $0.563(0.497)$ & $0.560(0.497)$ & 0.932 \\
\hline White & $0.687(0.464)$ & $0.708(0.455)$ & 0.476 \\
\hline Black & $0.118(0.323)$ & $0.099(0.299)$ & 0.366 \\
\hline Asian & $0.078(0.268)$ & $0.091(0.288)$ & 0.466 \\
\hline Multiple or other race & $0.118(0.323)$ & $0.101(0.302)$ & 0.426 \\
\hline High school diploma or lower & $0.080(0.271)$ & $0.070(0.255)$ & 0.556 \\
\hline Some college & $0.179(0.383)$ & $0.266(0.443)$ & $<0.01 * *$ \\
\hline College diploma or higher & $0.742(0.438)$ & $0.664(0.473)$ & $<0.01 * *$ \\
\hline 2019 household income: less than $\$ 25,000$ & $0.143(0.350)$ & $0.127(0.333)$ & 0.471 \\
\hline 2019 household income: $\$ 25,000-\$ 34,999$ & $0.113(0.317)$ & $0.140(0.347)$ & 0.227 \\
\hline 2019 household income: $\$ 35,000-\$ 49,999$ & $0.170(0.376)$ & $0.195(0.396)$ & 0.332 \\
\hline 2019 household income: $\$ 50,000-\$ 74,999$ & $0.263(0.441$ & $0.266(0.443)$ & 0.895 \\
\hline 2019 household income: $\$ 75,000-\$ 99,999$ & $0.174(0.380)$ & $0.142(0.349)$ & 0.168 \\
\hline 2019 household income: more than $\$ 100,000$ & $0.137(0.344)$ & $0.131(0.338)$ & 0.805 \\
\hline Crime victim (in past 12 months) & $0.122(0.327)$ & $0.125(0.331)$ & 0.893 \\
\hline Feel safe walking at night (own neighborhood) & $0.792(0.406)$ & $0.770(0.422)$ & 0.404 \\
\hline Time to finish survey (in seconds) & $177.151(166.159)$ & $167.617(152.304)$ & 0.357 \\
\hline \multicolumn{4}{|l|}{ (b) Panel B: outcome variables } \\
\hline Feel unsafe walking at night (street in photo) & $0.290(0.454)$ & $0.372(0.484)$ & $<0.01 * *$ \\
\hline Stay at home because worried about safety & $0.218(0.414)$ & $0.243(0.429)$ & 0.368 \\
\hline $\begin{array}{l}\text { Stay at home because worried about safety or take } \\
\text { taxi }\end{array}$ & $0.439(0.497)$ & $0.461(0.499)$ & 0.500 \\
\hline \# of nights outdoors (per week) & $2.748(1.189)$ & $2.77(1.864)$ & 0.856 \\
\hline
\end{tabular}

Table presents covariate means and standard errors for the treatment group (the photo featuring LED lighting) and the control group (the photo featuring 'business-as-usual' lighting). For each variable, we provide the $p$-value from a $t$-test that tests the equality of the group means

Significance: $* p<0.05, * * p<0.01$

\section{Results}

\section{Summary statistics}

Table 1 presents descriptive statistics for our study sample of $N=949$ respondents who passed the attention check question. In total, there are 476 respondents in the treatment (LED) group and 473 respondents in the control (business-as-usual) group. In Panel A we present descriptive statistics for respondent characteristics; in Panel B we present descriptive statistics for our four primary outcomes. Means and standard deviations (in parentheses) are presented separately for the treatment and 
control groups. On average, sample respondents were 36 years old and $56 \%$ of the sample is male. With respect to race, $70 \%$ of the sample is White, $11 \%$ is Black, $8 \%$ is Asian, and another $11 \%$ of respondents indicated either that they were Hispanic or that they identify with multiple ancestry groups. $70 \%$ of our sample are college graduates and income varies considerably among the sample with nearly one third of respondents living in households earning more than $\$ 75,000$ and more than one quarter living in households earning less than $\$ 35,000$. $12 \%$ of respondents indicated that they have been the victim of a crime during the past 12 months which is similar to the prevalence rate of violent and property crimes in the National Crime Victimization Survey. More than three quarters of the sample generally feels safe walking around at night in their own neighborhoods. On average, it took respondents just under 3 minutes to complete the survey.

With respect to our four primary outcome measures, among the control group, $37 \%$ of respondents who were assigned to view the business-as-usual photo report that they would feel unsafe being outdoors during nighttime hours. Among the treatment group, the proportion is $29 \%$, a difference that is significant at the $\alpha=0.01$ level. In response to the vignette question, across the two groups, $23 \%$ of respondents indicated that they would remain at home due to concerns for their safety and nearly half of respondents indicated that they would either remain at home or that they would take a taxi/rideshare even though their destination is only a short walk away. Respondents in both groups indicated that they would, on average, spend 2.8 nights per week outside their home, having viewed their assigned photo.

\section{Fidelity of Randomization}

Respondents are randomized to the treatment or control condition using Qualtrics survey software. ${ }^{14}$ In this section, we provide evidence that the randomization was faithfully carried out by showing that respondent attributes are balanced evenly across the treatment and control conditions. For each covariate, Table 1 reports the $p$-value from a $t$-test of the equality of the sample means across the two randomly assigned treatment groups. Most of the $p$-values are large and, with only a single exception, are not significant at conventional levels of significance. The exception is education-individuals in the control group are less likely to be college educated. In order to construct an omnibus test of covariate balance, we regress the binary treatment indicator on the full vector of covariates and compute the $F$-statistic which tests for the joint significance of covariates in predicting treatment status. The $p$-value on the $F$-statistic is 0.25 , indicating that there is little evidence against the null hypothesis of successful randomization. As indicated in "Survey experiment", we condition on covariates to account for any remaining imbalances between treatment and control respondents.

\footnotetext{
${ }^{14}$ We use the "Randomizer" setting in Qualtrics to randomly present either the photo showing the light street or the dark street to respondents. This tool is built into Qualtrics and will evenly assign the possible choices - in our case the two photos-to respondents so the final sample has a similar number of people in each group.
} 
Table 2 Survey sample versus the U.S. population

\begin{tabular}{lll}
\hline & Survey sample & U.S. population \\
\hline Age (median) & 34.0 & 37.9 \\
Male & $56 \%$ & $49 \%$ \\
White & $70 \%$ & $73 \%$ \\
Black & $11 \%$ & $13 \%$ \\
Asian & $8 \%$ & $5 \%$ \\
High school diploma or higher & $99 \%$ & $88 \%$ \\
Income $<\$ 25,000$ & $13 \%$ & $20 \%$ \\
Income $>\$ 100,000$ & $13 \%$ & $28 \%$ \\
Crime victim in past 12 months & $12 \%$ & $13 \%$ \\
\hline
\end{tabular}

Table presents covariate means and standard errors for the survey sample along with estimated means for the U.S. population. Data on age, gender, race and education come from the 2014-2018 American Communities Survey 5-Year Data Profile (https://www.census. gov/acs/www/data/data-tables-and-tools/data-profiles/); data on victimization come from the 2018 National Crime Victimization Survey which reported a rate per 1000 people of 23.2 violent victimizations and 108.2 property victimizations (https://www.bjs.gov/content/pub/ pdf/cv18.pdf)

\section{External validity}

Next, we consider the robustness of the results to two dimensions of external validity. First, we consider the extent to which the survey sample obtained via Amazon MTurk is representative of the U.S. population as a whole. While we are unable to test this proposition along all possible dimensions, we can compare our study sample to the general population with respect to the covariates we have gathered. This information is presented in Table 2. As is evident from the table, our sample is broadly balanced with respect to age and race though our sample is more male and is less likely to include both individuals without a high school degree or individuals living in households earning more than $\$ 100,000$. We present all subsequent estimates both using raw survey data as well as using survey weights which ensure that our sample resembles the U.S. population. Second, recognizing that the survey was administered during the COVID-19 pandemic, we use data from a small-scale pilot of our survey experiment which we administered to $N=78$ respondents on February 25th, 2020 to assess the extent to which our data are contaminated by the COVID-19 pandemic and subsequent events. The results of this exercise confirm that survey responses do not differ significantly between the pilot sample and the analytic sample. Additional detail is provided in Appendix A. 
Table 3 Main results

\begin{tabular}{|c|c|c|c|c|}
\hline & $\begin{array}{l}\text { Feel unsafe } \\
\text { walking at } \\
\text { night }\end{array}$ & $\begin{array}{l}\text { Stay at home because } \\
\text { worried about safety }\end{array}$ & $\begin{array}{l}\text { Stay at home because } \\
\text { worried about safety or } \\
\text { take taxi }\end{array}$ & $\begin{array}{l}\text { \# of nights } \\
\text { outdoors (per } \\
\text { week) }\end{array}$ \\
\hline Treatment (more light) & $\begin{array}{l}-0.078^{*} \\
(0.031)\end{array}$ & $\begin{array}{l}-0.029 \\
(0.023)\end{array}$ & $\begin{array}{l}-0.023 \\
(0.026)\end{array}$ & $\begin{array}{l}-0.075 \\
(0.079)\end{array}$ \\
\hline Age & $\begin{array}{l}-0.009 \\
(0.006)\end{array}$ & $\begin{array}{l}-0.007 \\
(0.006)\end{array}$ & $\begin{array}{l}-0.022 * * \\
(0.007)\end{array}$ & $\begin{array}{l}-0.000 \\
(0.024)\end{array}$ \\
\hline Age squared & $\begin{array}{l}0.000 * \\
(0.000)\end{array}$ & $\begin{array}{l}0.000 \\
(0.000)\end{array}$ & $\begin{array}{l}0.000 * * \\
(0.000)\end{array}$ & $\begin{array}{l}-0.000 \\
(0.000)\end{array}$ \\
\hline Male & $\begin{array}{l}-0.157 * * \\
(0.029)\end{array}$ & $\begin{array}{l}-0.063^{*} \\
(0.025)\end{array}$ & $\begin{array}{l}-0.113 * * \\
(0.024)\end{array}$ & $\begin{array}{l}0.274 * * \\
(0.085)\end{array}$ \\
\hline Black & $\begin{array}{l}-0.101^{*} \\
(0.045)\end{array}$ & $\begin{array}{l}0.089 * \\
(0.039)\end{array}$ & $\begin{array}{l}0.167 * \\
(0.067)\end{array}$ & $\begin{array}{l}0.015 \\
(0.166)\end{array}$ \\
\hline Asian & $\begin{array}{l}-0.019 \\
(0.058)\end{array}$ & $\begin{array}{l}-0.003 \\
(0.035)\end{array}$ & $\begin{array}{l}0.085^{*} \\
(0.041)\end{array}$ & $\begin{array}{l}-0.813 * * \\
(0.177)\end{array}$ \\
\hline Multiple or other race & $\begin{array}{l}0.025 \\
(0.051)\end{array}$ & $\begin{array}{l}-0.020 \\
(0.039)\end{array}$ & $\begin{array}{l}-0.021 \\
(0.039)\end{array}$ & $\begin{array}{l}0.038 \\
(0.128)\end{array}$ \\
\hline Some college & $\begin{array}{l}-0.051 \\
(0.073)\end{array}$ & $\begin{array}{l}-0.043 \\
(0.045)\end{array}$ & $\begin{array}{l}-0.073 \\
(0.046)\end{array}$ & $\begin{array}{l}-0.006 \\
(0.218)\end{array}$ \\
\hline $\begin{array}{l}\text { College diploma or } \\
\text { higher }\end{array}$ & $\begin{array}{l}-0.052 \\
(0.069)\end{array}$ & $\begin{array}{l}0.067 \\
(0.051)\end{array}$ & $\begin{array}{l}-0.058 \\
(0.048)\end{array}$ & $\begin{array}{l}0.430 \\
(0.232)\end{array}$ \\
\hline $\begin{array}{l}\text { Income: less than } \\
\$ 25,000\end{array}$ & $\begin{array}{l}-0.006 \\
(0.062)\end{array}$ & $\begin{array}{l}0.138 * * \\
(0.039)\end{array}$ & $\begin{array}{l}0.065 \\
(0.048)\end{array}$ & $\begin{array}{l}0.159 \\
(0.200)\end{array}$ \\
\hline $\begin{array}{l}\text { Income: } \$ 25,000- \\
\quad \$ 34,999\end{array}$ & $\begin{array}{l}-0.074 \\
(0.051)\end{array}$ & $\begin{array}{l}0.186 * * \\
(0.054)\end{array}$ & $\begin{array}{l}0.100^{*} \\
(0.040)\end{array}$ & $\begin{array}{l}0.310 \\
(0.169)\end{array}$ \\
\hline $\begin{array}{l}\text { Income: } \$ 35,000- \\
\quad \$ 49,999\end{array}$ & $\begin{array}{l}-0.079 \\
(0.053)\end{array}$ & $\begin{array}{l}0.105^{*} \\
(0.044)\end{array}$ & $\begin{array}{l}0.032 \\
(0.052)\end{array}$ & $\begin{array}{l}0.431 * * \\
(0.126)\end{array}$ \\
\hline $\begin{array}{l}\text { Income: } \$ 50,000- \\
\quad \$ 74,999\end{array}$ & $\begin{array}{l}-0.021 \\
(0.048)\end{array}$ & $\begin{array}{l}0.130 * * \\
(0.031)\end{array}$ & $\begin{array}{l}0.062 \\
(0.039)\end{array}$ & $\begin{array}{l}0.550 * * \\
(0.165)\end{array}$ \\
\hline $\begin{array}{l}\text { Income: } \$ 75,000- \\
\quad \$ 99,999\end{array}$ & $\begin{array}{l}-0.031 \\
(0.051)\end{array}$ & $\begin{array}{l}0.094 * \\
(0.036)\end{array}$ & $\begin{array}{l}0.113 * * \\
(0.038)\end{array}$ & $\begin{array}{l}0.145 \\
(0.219)\end{array}$ \\
\hline Crime victim & $\begin{array}{l}0.032 \\
(0.041)\end{array}$ & $\begin{array}{l}0.044 \\
(0.047)\end{array}$ & $\begin{array}{l}-0.024 \\
(0.052)\end{array}$ & $\begin{array}{l}1.466 * * \\
(0.145)\end{array}$ \\
\hline $\begin{array}{l}\text { Feel safe walking at } \\
\text { night }\end{array}$ & $\begin{array}{l}-0.362^{* *} \\
(0.043)\end{array}$ & $\begin{array}{l}-0.207 * * \\
(0.030)\end{array}$ & $\begin{array}{l}-0.261 * * \\
(0.040)\end{array}$ & $\begin{array}{l}1.032 * * \\
(0.138)\end{array}$ \\
\hline
\end{tabular}

Table presents coefficients along with clustered standard errors in parentheses from the following least squares regression model: $Y_{i}^{j}=\alpha+\beta^{j} D_{i}+\gamma X_{i}+\varepsilon_{i}$. In the model, $D_{i}$ is the treatment indicator for the LED version of the photo and $\beta^{j}$ is the average treatment effect for outcome $j$.

Significance: $* p<0.05, * * p<0.01$ 


\section{Main results}

In Table 3, we present regression estimates derived from equation (1) using the raw survey data. In the table, least squares coefficients are reported alongside clustered standard errors in parentheses. Each column corresponds with a different outcome variable. We begin with the effect of the treatment (the LED version of the photo) on whether or not a respondent reports feeling unsafe walking at night. Relative to a base rate of $37 \%$ among the control group, respondents who were randomly assigned to the LED version of the photo were $7.8 \%$ points $(21 \%)$ less likely to report feeling unsafe. Several other points are worth noting. First, controlling for treatment assignment, concerns about safety rise with age and are greater among female than among male respondents. Both of these findings accord with the large descriptive literature on fear of crime (Roman and Chalfin 2008; Roman et al. 2009). Second, Black respondents are less likely to report feeling unsafe than White respondents. Third, individuals who reported that they had been the victim of a crime during the prior 12 months do not appear to be especially likely to report feeling unsafe though standard errors are not small enough to rule out a modest association. Finally, individuals who report that they feel safe walking in their own neighborhood after dark are substantially less likely to report that they would feel unsafe given the photo they were assigned to view. This is sensible as a great deal of the variation in perceptions of safety will naturally be due to person-level heterogeneity. Overall, the model explains just over $17 \%$ of the variation in feelings of safety.

Next, we consider whether survey respondents' self-reported precautionary behaviors are affected by their assignment to view the treatment versus the control version of the photo. In columns (2) and (3), we consider the vignette exercise in which, upon viewing the randomly assigned photo, respondents were asked to indicate whether and, if so, how they might travel to a friend's home after dark. Relative to a base rate of $24 \%$, respondents in the treatment group were $2.9 \%$ points less likely to indicate that they would remain at home due to concerns for their safety. Likewise, relative to a base rate of $46 \%$, respondents were $2.3 \%$ points less likely to indicate either that they would remain at home due to safety concerns or that they would take a taxi/rideshare to travel just a few blocks. While the point estimates suggest that more lighting might lead to a small increase in the use of public space at night, the estimates are not significant at conventional levels of significance. Given that the standard error in model (3) is 0.026 , we can be $95 \%$ confident that the true effect of the LED lighting on the use of public space is not greater than $11 \%$. Finally, referring to column (4), we see very little evidence that respondents in the treatment and control conditions would spend a different number of days outside their home.

We present alternative estimates in Appendix B. First, we report estimates from weighted least squares models in which we re-weight the survey data to resemble the U.S. population with respect to age, race and gender. Next, we present estimates of the treatment effect for feelings of safety under a number of alternative functional forms. In all cases, estimates are substantively similar to those reported in Table 3. 
Table 4 Treatment effect heterogeneity

\begin{tabular}{|c|c|c|c|c|}
\hline & $\begin{array}{l}\text { Feel unsafe } \\
\text { walking at } \\
\text { night }\end{array}$ & $\begin{array}{l}\text { Stay at home because } \\
\text { worried about safety }\end{array}$ & $\begin{array}{l}\text { Stay at home because } \\
\text { worried about safety or } \\
\text { take taxi }\end{array}$ & $\begin{array}{l}\text { \# of Nights } \\
\text { Outdoors (per } \\
\text { week) }\end{array}$ \\
\hline \multirow[t]{2}{*}{ Age } & 0.004 & 0.000 & 0.003 & -0.012 \\
\hline & (0.004) & $(0.003)$ & $(0.003)$ & $(0.013)$ \\
\hline \multirow[t]{2}{*}{ Male } & -0.008 & 0.059 & 0.047 & -0.084 \\
\hline & $(0.067)$ & $(0.050)$ & $(0.066)$ & $(0.303)$ \\
\hline \multirow[t]{2}{*}{ Black } & -0.047 & 0.073 & -0.047 & -0.028 \\
\hline & $(0.109)$ & $(0.077)$ & $(0.143)$ & $(0.436)$ \\
\hline \multirow[t]{2}{*}{ Income $>\$ 75,000$} & -0.010 & 0.029 & -0.002 & 0.114 \\
\hline & $(0.062)$ & $(0.043)$ & $(0.064)$ & $(0.264)$ \\
\hline \multirow[t]{2}{*}{ Crime victim } & 0.139 & 0.033 & 0.072 & $-0.84 * *$ \\
\hline & $(0.076)$ & $(0.089)$ & $(0.108)$ & $(0.299)$ \\
\hline
\end{tabular}

Table presents coefficients along with clustered standard errors in parentheses from the following least squares regression model: $Y_{i}^{j}=\alpha+\beta^{j} D_{i}+\gamma X_{i}+\rho^{j} X_{i} D_{i}+\varepsilon_{i}$. In the model, $D_{i}$ is the treatment indicator for the LED version of the photo and $X_{i}$ is a covariate of interest. The table reports $\rho^{j}$ along with its standard error for each of five selected covariates and four outcome variables

Significance: ${ }^{*} p<0.05, * * p<0.01$

\section{Treatment effect heterogeneity}

Next, we test for treatment effect heterogeneity with respect to a subset of theoretically important covariates: age, gender, race, income and previous victimization. We limit the number of covariates tested to reduce the number of tests and therefore the probability of false discoveries. As in all experiments, constraints on statistical power mean that our ability to detect meaningful interaction effects is more limited than it is for the main effects. For each of our four primary outcome variables, the coefficient on the interaction term between treatment and the covariate of interest along with its clustered standard error is presented in Table 4. Overall, there is little evidence for treatment effect heterogeneity for any of our four outcomes. With respect to feelings of safety-the outcome variable for which there was an important and statistically significant main effect-the evidence suggests that these effects are broad-based and accrue equally by age, gender, race and income. With respect to prior victimization, there is some speculative evidence that individuals who were victimized within the prior year do not respond to enhanced lighting in the same way that other individuals do, though the result is not significant at conventional levels. The crime victim coefficient is significant and negative with respect to the number of nights per week that victims indicate they will spend outdoors. However, the result is no longer significant after applying a Bonferroni correction to account for multiple hypothesis testing. 

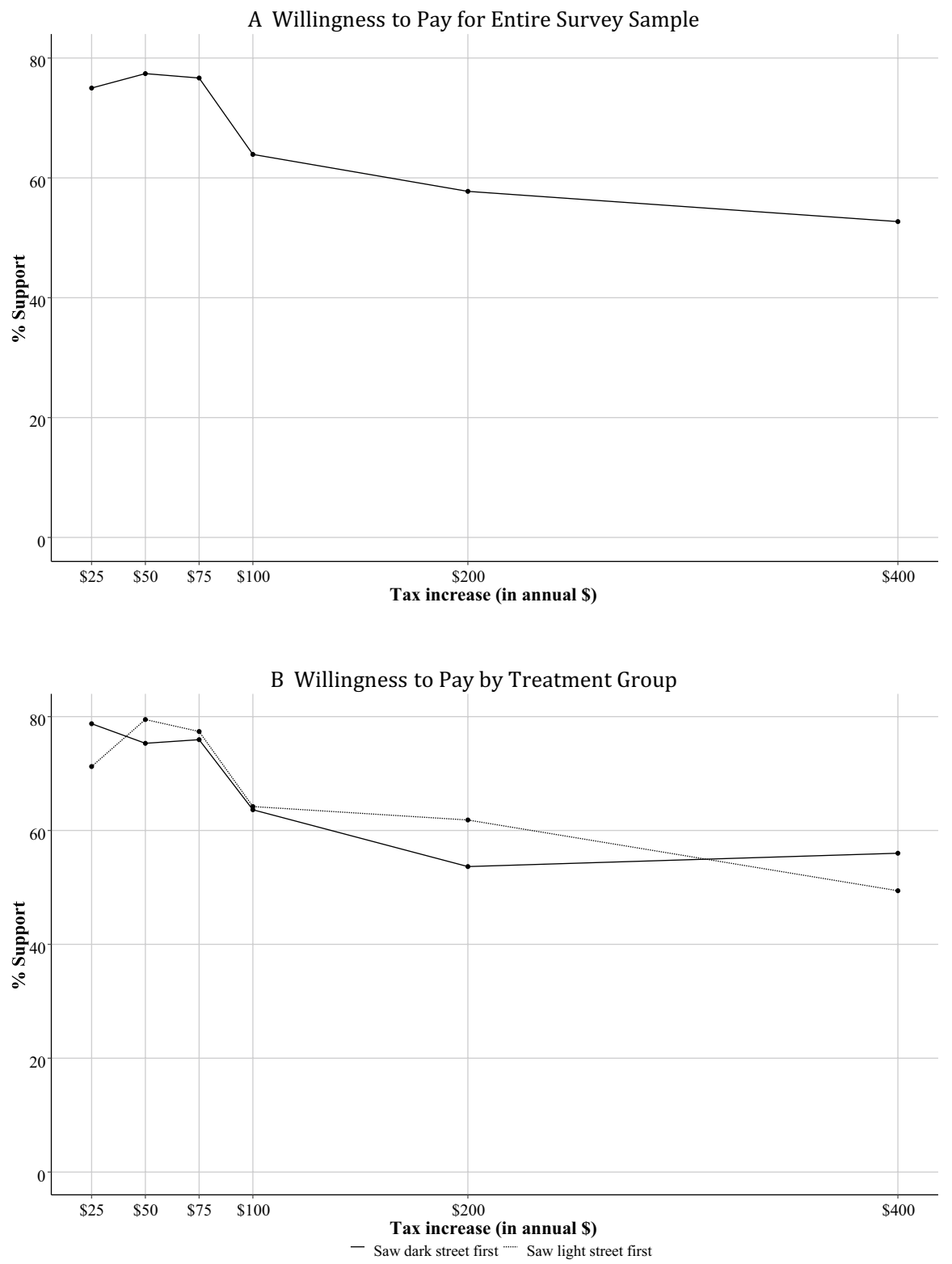

Fig. 2 Willingness to pay for streetlight improvements

\section{Willingness-to-pay}

Finally, we turn to estimates of respondents' willingness to pay for a municipal program to brighten street lights. Recall that respondents were asked whether or not they would be willing to pay an additional $\$ k$ in taxes to support a program that 
brings street lighting in their community from the control ("business-asusual") condition to the treatment (LED) condition. Each respondent is randomly assigned to react to a different value of $k$. Critically, this allows us to plot the share of individuals who are willing to support the lighting program for each value of $k$ without worrying that $k$ varies with respondent characteristics. Results of our willingness-to-pay analysis are presented graphically in Fig. 2 which plots a quasi-demand curve for a lighting upgrade from the business-as-usual condition to the LED condition. Panel A presents results for the full sample. We see that the slope of the curve is negative indicating that support for the program falls as the price rises. Overall, nearly $80 \%$ of respondents indicate that they would pay at least $\$ 75$ for the lighting upgrade suggested by the survey question. Interestingly, this is roughly equal to the share of respondents who would pay $\$ 25$ for the lighting upgrade suggesting that a modest number of people are unwilling to support capital improvements to street lighting at any price. Demand for lighting falls with $k$ over the remainder of the values. Still, $53 \%$ of respondents indicate that they would be willing to pay $\$ 400$ - or just over $\$ 1$ per day - to fund a capital upgrade to street lighting. In Fig. 2, Panel B, we assess whether estimates differ according to whether a respondent was initially assigned to the treatment or the control condition. We see little evidence for a priming effect thus providing support for the proposition that willingness-to-pay for street lighting is reasonably stable.

Finally, we assess whether willingness-to-pay differs by demographic characteristics. We do so by regressing minimum willingness to pay on our vector of covariates. Overall, we find that men are willing to pay $\$ 14$ less than women $(p<0.06)$ and that while there is no Black-White difference in WTP, Asian respondents were willing to pay $\$ 40$ less than White respondents. College-educated respondents were, on the other hand, willing to pay more $(\$ 24)$ for the program than those without a college degree. Whether or not we condition on covariates, there is only limited evidence that willingness to pay for the program rises with income which is perhaps surprising given that lower-income respondents have less disposable income. Finally, we note that individuals who report a recent victimization are actually less willing to pay $\$ 38$ less for the hypothetical lighting intervention than respondents who had not been recently victimized. While we can only speculate as to the reasons behind this association, one possibility is that these individuals do not believe that better lighting would have prevented their victimization which causes them to be especially skeptical.

\section{Discussion}

To our knowledge, this study provides the first estimate in the United States for how much people are willing to pay to improve the brightness of street lighting with the goal of improving public safety. While other research evaluates people's willingness to pay to reduce crime broadly, such studies typically ask survey respondents about unnamed programs that would reduce crime by a certain amount (Ludwig and Cook 2001; Cohen et al. 2004; Loomes 2007; Bishop and Murphy 2011; Cohen 2015; Stickle 2015; Baker et al. 2016; Brenig and Proeger 2018; Piquero and Steinberg 
2010; Lee and Fisher 2020). ${ }^{15}$ Perhaps surprisingly the approach has rarely been used in the CPTED literature. Policies that are intended to change the built or physical environment-for example, cleaning and greening vacant lots (Kondo et al. 2016; Branas et al. 2018), installing security cameras (Alexandrie 2017), and installing burglar-resistant doors and windows in homes (Vollaard and Van Ours 2011) often have a known cost to install and maintain, and a growing body of evidence as to their effectiveness. This provides a useful "real cost" comparison for future willingness-to-pay studies to evaluate whether the public is willing to pay more than the cost of the intervention and allow policy makers to prioritize interventions that are both shown to be effective in research and supported by the public. The ability to create experimental vignettes in survey software also provides an opportunity for researchers to better assess how the context and the dosages of intervention affects public support. For example, a study that assesses willingness-to-pay for cleaning and greening vacant lots could provide a number of possible options for how the lot would look and would provide more actionable evidence on public opinion than merely a binary option.

The remainder of this article considers how these findings inform our understanding of potential victims and the promise of place-based crime control strategies. Several points are worth noting. First, consistent with the majority of the prior research, ambient lighting makes people feel safer (Vrij and Winkel 1991; Painter 1996) and leads to improvements in general well-being (Hanslmaier 2013). ${ }^{16}$ On the other hand, there is little evidence that policing targeted to crime hot spots has the same ancillary benefits (Kochel and Weisburd 2017; Ratcliffe et al. 2015). Indeed, there continue to be evidence-based concerns that, even though police presence leads to meaningful reductions in crime (MacDonald et al. 2012, 2016; Weisburd 2016; Heaton et al. 2016; Ridgeway et al. 2019), the concentration of police personnel at crime hot spots may have deleterious impacts on the well-being of affected communities (Rosenbaum 2006; Weisburd et al. 2011). Given the evidence that crime is responsive to ambient lighting (Doleac and Sanders 2015; Davies and Farrington 2018; Chalfin et al. 2020; Domínguez and Asahi 2019; Chalfin et al. 2021) investments in street lighting potentially offers policymakers a viable means of controlling crime while, at the same time, improving community perceptions of safety.

\footnotetext{
${ }^{15}$ In a few cases, a more specific policy is referenced-see Cohen et al. (2006), Nagin et al. (2006) and Dunbar (2020). The programs used in these studies are often increasing the size of the police force, youth prevention programs, or building prisons. As each of these policies can vary dramatically in the size of the intervention (e.g., how many officers hired) or the type of intervention (e.g. how officers are deployed), there remains great opportunity to study these outcomes with more specific descriptions of the intervention used.

${ }^{16}$ Precisely how lighting affects fear and perceived safety remains poorly understood. However, evidence from an experiment by Haans and De Kort (2012) indicates that, whether they are stationary or walking, individuals prefer having light in their own immediate surroundings rather than on the road that lies ahead. One implication of this finding is that lighting enhances safety primarily by giving a potential victim the ability to respond effectively to dangerous events rather than by allowing victims to more effectively avert risks that lie ahead. A second implication of this finding is that potential victims value visibility over concealment.
} 
Second, the results suggest that individuals prefer to internalize feelings of unease rather than change their behavior in order to mitigate risk. This result is consistent with a variety of theoretical and empirical evidence which suggests that because individuals do not fully internalize the cost of victimization (Clotfelter 1978; Ayres and Levitt 1998; Clements 2003), because public spending on crime control may be treated as a subsidy (Guha and Guha 2012) or because individuals are myopic or misinformed-victims may under-invest in precaution, relative to what is socially optimal (Chalfin et al. 2019). This finding is likewise consistent with a host of additional CPTED-related research which suggests that individuals do not engage in even the least costly precautions even though they can reasonably expect that such investments will reduce their risk of victimization. A particularly common example of this type of behavior can be found in the large share of burglaries and car break-ins in which the target location was unlocked (Bopp 1986; Budd 1999; Weisel 2002).

Why might individuals be unwilling to take greater precautions when lighting is poor? One possibility is that individuals have trouble differentiating between their own level of risk and the risk that society faces more generally (Rothman et al. 1996). Another possibility is that individuals are present-oriented and place little value on future risks (Thaler and Sunstein 2009), especially when those risks are uncertain (Mengel et al. 2016). A third possibility is that individuals may have an aversion to subsuming costs which they feel are being unfairly transferred to them by offenders. The latter point is one means of rationalizing our finding that many individuals who are unwilling to take greater precaution personally are nevertheless willing to generously support a publicly-financed lighting program. The implication is that many individuals believe that the costs of crime control should be socialized rather than internalized by potential victims.

Finally, with respect to municipal investments in place-based crime control strategies, in contrast with some prior research which finds that use of public space rises after lighting upgrades, the results of our survey experiment indicate that plans to use public space are relatively insensitive to lighting conditions. On the one hand, this finding highlights the promise of municipal street lighting as a means of maintaining public safety without generating efficiency losses due to compensatory behaviors among potential crime victims. On the other hand, this finding is considerably less optimistic with respect to concerns that fear of crime interferes with active and healthy living (Roman et al. 2009; Shinew et al. 2013; Esteban-Cornejo et al. 2016). Our contingent valuation survey suggests that there may be untapped demand for investments in enhanced street lighting, especially in an era in which policymakers and increasingly many members of the public are interested in identifying ways to maintain public safety in high-crime places without continuing to invest in enforcement-based strategies.

We close with a discussion of research limitations and recommendations for future research. With respect to the external validity of our survey experiment, a natural limitation is that we examine preferences over lighting using a single photo 
of a particular block in a particular large U.S. city. ${ }^{17}$ Future research should examine other contexts for changes in lighting, such as lighting improvements around parks, schools, or commercial buildings such as bars. As recent research has found that the dosage of lighting can have profound implications for the crime effects of street lighting (Chalfin et al. 2020, 2021), future research should also vary the amount of lighting that is altered. This can help ascertain the minimum amount of light necessary to improve criminal justice outcomes, making improvements to outdoor lighting more efficient. In addition, recent research in criminology has used virtual reality to try to create more realistic scenarios for experimental research (Groff et al. 2005; Ticknor and Tillinghast 2011; Van Gelder et al. 2014; Liao et al. 2016; Van Gelder et al. 2017, 2019). Use of this technology (or even video or panoramic photos of an area) could more realistically depict the change in lighting to respondents than a photo, making results from such a study better reflect real world changes.

With respect to contingent valuation, several items are worth noting. First, consistent with standard practice in contingent valuation surveys in the criminal justice domain, we ask respondents about their willingness to pay for improved lighting but do not consider their willingness to expend resources on other potential interventions. Given that respondents may be willing to pay for lighting improvements, but still prioritize spending on other policies, this study provides useful, albeit incomplete, evidence on the methods and modes through which individuals would like to invest in public safety. Future work which provides survey respondents with a menu of potential alternatives will be of considerable value especially given recent calls to identify alternatives to investments in law enforcement (Weichselbaum and Lewis 2020). Studies that, for example, ask respondents to allocate a set amount of money among a number of possible policies could allow policymakers to better prioritize popular programs and could address concerns that traditionally popular programs — such as spending on law enforcement—should receive less funding in favor of alternatives.

\section{Conclusion}

This research presents the results of a survey experiment which tests the sensitivity of individuals' feelings of safety and their willingness to use public space to improvements in nighttime ambient lighting. We find that individuals who were randomly assigned to view a photo of a city street which had received enhanced LED lighting expressed less fear of spending time outdoors than individuals who were randomly assigned to view a photo of the same street under business-as-usual lighting conditions. The effects are broad-based and hold equally strongly for men and women, for Black and White respondents and for respondents of all education and income levels. On the other hand, consistent with findings in Atkins et al. (1991) but in contrast with those in Painter (1996) and Painter and Farrington (1999b), we observe little evidence for differences in the way that individuals in the treatment

17 Though the city is not named, the skyscraper in the background suggests that it is an urban setting. 
and control groups planned to use public space or the extent to which they are willing to engage in costly activities-e.g., remaining at home or taking a taxi-in order to mitigate victimization risk. Interestingly our contingent valuation estimates suggest that just over half of respondents would be willing to pay at least $\$ 400$ and nearly $80 \%$ would pay at least $\$ 75$ per year for enhanced street lighting which raises several interesting questions about under what conditions potential victims are willing to bear the costs of crime control.

These results suggest that there may be broad public support for the capital improvement projects that a number of major cities are undertaking in the United States to improve the brightness of their street lights. Indeed, our contingent valuation survey suggests that a majority of respondents are willing to pay more than cities have, in recent years, spent to upgrade their street lighting infrastructure. Such multi-year projects, which seek to replace all or most of the city's street lights with brighter LED lighting — similar to the intervention studied in this paper-range from per capita costs of \$9 in New York City (Gregory 2013) to \$275 in Detroit (Trickey 2017), with most costing below $\$ 60$ per resident over the course of the project. ${ }^{18}$ As the price of LED lights have steadily decreased over the last decade (Chen 2018), the price of replacing street lights may continue to decline in the future.

Supplementary Information The online version contains supplementary material available at https://doi. org/10.1057/s41284-021-00296-0.

\section{Declarations}

Conflict of interest The author declare that they have no conflict of interest.

\section{References}

Akers, R.L. 1990. Rational choice, deterrence, and social learning theory in criminology: The path not taken. Journal of Criminal Law \& Criminology 81: 653.

Alexandrie, G. 2017. Surveillance cameras and crime: A review of randomized and natural experiments. Journal of Scandinavian Studies in Criminology and Crime Prevention 18 (2): 210-222.

Angrist, J.D., and J.-S. Pischke. 2008. Mostly Harmless Econometrics: An empiricist's companion. Princeton: Princeton University Press.

Apel, R., G. Pogarsky, and L. Bates. 2009. The sanctions-perceptions link in a model of school-based deterrence. Journal of Quantitative Criminology 25 (2): 201-226.

Arrow, K., R. Solow, P.R. Portney, E.E. Leamer, R. Radner, H. Schuman, et al. 1993. Report of the NOAA panel on contingent valuation. Federal Register 58 (10): 4601-4614.

Arvate, P., F.O. Falsete, F.G. Ribeiro, and A.P. Souza. 2018. Lighting and homicides: evaluating the effect of an electrification policy in rural Brazil on violent crime reduction. Journal of Quantitative Criminology 34 (4): 1047-1078.

Atkins, S., S. Husain, and A. Storey (1991). The influence of street lighting on crime and fear of crime. United Kingdom Home Office.

\footnotetext{
18 In Los Angeles the cost is \$14 per person to replace 80\% of street lights (Maddox 2016). In the small city of Clifton Park, New York, the cost to replace all of their street lights is \$31 per person (Liberatore 2018). Chicago-whose lighting improvement this study directly assesses - is spending $\$ 59$ per person to replace $85 \%$ of their streetlights (Shueh 2017).
} 
Ayres, I., and S.D. Levitt. 1998. Measuring positive externalities from unobservable victim precaution: An empirical analysis of lojack. The Quarterly Journal of Economics 113 (1): 43-77.

Baker, T., H.M. Cleary, J.T. Pickett, and M.G. Gertz. 2016. Crime salience and public willingness to pay for child saving and juvenile punishment. Crime \& Delinquency 62 (5): 645-668.

Baumer, E.P., and J.L. Lauritsen. 2010. Reporting crime to the police, 1973-2005: A multivariate analysis of long-term trends in the National Crime Survey (NCS) and National Crime Victimization Survey (NCVS). Criminology 48 (1): 131-185.

Becker, G.S. 1968. Crime and punishment: An economic approach. The Journal of Political Economy 76 (2): 169-217.

Berryessa, C.M. 2017. Jury-eligible public attitudes toward biological risk factors for the development of criminal behavior and implications for capital sentencing. Criminal Justice and Behavior 44 (8): 1073-1100.

Berryessa, C.M. 2018. The effects of psychiatric and "biological" labels on lay sentencing and punishment decisions. Journal of Experimental Criminology 14 (2): 241-256.

Berryessa, C.M., J.A. Chandler, and P. Reiner. 2016. Public attitudes toward legally coerced biological treatments of criminals. Journal of Law and the Biosciences 3 (3): 447-467.

Bishop, K.C., and A.D. Murphy. 2011. Estimating the willingness to pay to avoid violent crime: A dynamic approach. American Economic Review 101 (3): 625-29.

Block, K., S. Ling, and J. Kaplan. 2020. Age, criminal punishment, and accountability: What the public recommends for guilty defendants. Working Paper.

Bopp, W.J. 1986. A profile of household burglary in America. The Police Journal 59 (2): 168-173.

Braga, A.A., A.V. Papachristos, and D.M. Hureau. 2014. The effects of hot spots policing on crime: An updated systematic review and meta-analysis. Justice Quarterly 31 (4): 633-663.

Braga, A.A., and D. Weisburd. 2010. Policing problem places: Crime hot spots and effective prevention. Oxford: Oxford University Press on Demand.

Branas, C.C., R.A. Cheney, J.M. MacDonald, V.W. Tam, T.D. Jackson, and T.R. Ten Have. 2011. A difference-in-differences analysis of health, safety, and greening vacant urban space. American Journal of Epidemiology 174 (11): 1296-1306.

Branas, C.C., D. Rubin, and W. Guo. 2012. Vacant properties and violence in neighborhoods. ISRN Public Health 2012.

Branas, C.C., E. South, M.C. Kondo, B.C. Hohl, P. Bourgois, D.J. Wiebe, and J.M. MacDonald. 2018. Citywide cluster randomized trial to restore blighted vacant land and its effects on violence, crime, and fear. Proceedings of the National Academy of Sciences 115 (12): 2946-2951.

Brenig, M., and T. Proeger. 2018. Putting a price tag on security: Subjective well-being and willingness to-pay for crime reduction in Europe. Journal of Happiness Studies 19 (1): 145-166.

Buckley, N., T. Frye, S. Gehlbach, and L.A. McCarthy. 2016. Cooperating with the state: Evidence from survey experiments on policing. Journal of Experimental Political Science 3 (2): 124-139.

Budd, T. 1999. Burglary of domestic dwellings: Findings from the British Crime Survey. Home Office Statistical Bulletin 4/99, Home Office, London.

Cacciatore, G., C. Fiandrino, D. Kliazovich, F. Granelli, and P. Bouvry. 2017. Cost analysis of smart lighting solutions for smart cities. In 2017 IEEE International Conference on Communications (ICC), pp. 1-6. IEEE.

Calvillo Cortés, A.B., and L.E. Falcón Morales. 2016. Emotions and the urban lighting environment: A cross-cultural comparison. SAGE Open 6 (1): 2158244016629708.

Cameron, T.A., and M.D. James. 1987. Efficient estimation methods for" closed-ended" contingent valuation surveys. The Review of Economics and Statistics 100: 269-276.

Carr, J.B., and J.L. Doleac. 2018. Keep the kids inside? Juvenile curfews and urban gun violence. The Review of Economics and Statistics 100 (4): 609-618.

Chalfin, A. 2015. Economic costs of crime. The Encyclopedia of Crime and Punishment, 1-12.

Chalfin, A., B. Hansen, J. Lerner, and L. Parker. 2020. Reducing crime through environmental design: Evidence from a randomized experiment of street lighting in New York City. Journal of Quantitative Criminology.

Chalfin, A., B. Hansen, and R. Ryley. 2019. The minimum legal drinking age and crime victimization. Technical report, National Bureau of Economic Research.

Chalfin, A., J. Kaplan, and M. LaForest. 2021. Street light outages, public safety and crime displacement: Evidence from Chicago. Working Paper. 
Chandler, J., P. Mueller, and G. Paolacci. 2014. Nonnaïveté among Amazon Mechanical Turk workers: Consequences and solutions for behavioral researchers. Behavior Research Methods 46 (1): $112-130$.

Chaudhuri, A. 2011. Sustaining cooperation in laboratory public goods experiments: A selective survey of the literature. Experimental Economics 14 (1): 47-83.

Chen, Y. (2018). Global led lighting products price trend. https://www.ledinside.com/news/2018/8/global led lighting

Clements, M.T. 2003. Precautionary incentives for privately informed victims. International Review of Law and Economics 23 (3): 237-251.

Clotfelter, C.T. 1978. Private security and the public safety. Journal of Urban Economics 5 (3): 388-402.

Cohen, L.E., and M. Felson. 1979. Social change and crime rate trends: A routine activity approach. American Sociological Review 44: 588-608.

Cohen, M.A. 2015. Willingness to pay to reduce white collar and corporate crime. Vanderbilt Law and Economics Research Paper (14-28).

Cohen, M.A., and A.R. Piquero. 2009. New evidence on the monetary value of saving a high risk youth. Journal of Quantitative Criminology 25 (1): 25-49.

Cohen, M.A., R.T. Rust, and S. Steen. 2006. Prevention, crime control or cash? Public preferences towards criminal justice spending priorities. Justice Quarterly 23 (3): 317-335.

Cohen, M.A., R.T. Rust, S. Steen, and S.T. Tidd. 2004. Willingness-to-pay for crime control programs. Criminology 42 (1): 89-110.

Coppock, A. 2019. Generalizing from survey experiments conducted on Mechanical Turk: A replication approach. Political Science Research and Methods 7 (3): 613-628.

Cozens, P., and T. Davies. 2013. Crime and residential security shutters in an Australian suburb: Exploring perceptions of 'eyes on the street', social interaction and personal safety. Crime Prevention and Community Safety 15 (3): 175-191.

Cozens, P. and D. Hillier. 2012. Revisiting Jane Jacobs's 'Eyes on the Street' for the twenty-first century: Evidence from environmental criminology. In The urban wisdom of Jane Jacobs, pp. 202-220. Routledge.

Cozens, P., G. Saville, and D. Hillier. 2005. Crime prevention through environmental design (CPTED): A review and modern bibliography. Property Management 23 (5): 328-356.

Cozens, P.M., R.H. Neale, J. Whitaker, D. Hillier, and M. Graham. 2003. A critical review of street lighting, crime and fear of crime in the British city. Crime Prevention and Community Safety 5 (2): 7-24.

Crosby, F., and F. Hermens. 2019. Does it look safe? An eye tracking study into the visual aspects of fear of crime. Quarterly Journal of Experimental Psychology 72 (3): 599-615.

Cruces, G., R. Perez-Truglia, and M. Tetaz. 2013. Biased perceptions of income distribution and preferences for redistribution: Evidence from a survey experiment. Journal of Public Economics 98: $100-112$.

Davies, M. W. and D. P. Farrington (2018). An examination of the effects on crime of switching off street lighting. Criminology \& Criminal Justice, 1748895818818861.

Doleac, J.L., and N.J. Sanders. 2015. Under the cover of darkness: How ambient light influences criminal activity. The Review of Economics and Statistics 97 (5): 1093-1103.

Dom’nnguez, P. and K. Asahi. 2019. Crime time: How ambient light affects crime. Technical report, IDB Working Paper Series.

Dunbar, A. 2020. Follow the money: Racial crime stereotypes and willingness to fund crime control policies. Psychology, Public Policy, and Law 26: 476-489.

Dunbar, A., and C.E. Kubrin. 2018. Imagining violent criminals: An experimental investigation of music stereotypes and character judgments. Journal of experimental criminology 14 (4): 507-528.

Ellis, S. 2007. Shedding light on late Roman housing. In Housing in Late Antiquity-Volume 3.2, pp. 283302. Brill.

Esteban-Cornejo, I., J.A. Carlson, T.L. Conway, K.L. Cain, B.E. Saelens, L.D. Frank, K. Glanz, C.G. Roman, and J.F. Sallis. 2016. Parental and adolescent perceptions of neighborhood safety related to adolescents' physical activity in their neighborhood. Research Quarterly for Exercise and Sport 87 (2): 191-199.

Farrington, D.P. 2003. Developmental and life-course criminology: Key theoretical and empirical issues the 2002 Sutherland Award address. Criminology 41 (2): 221-225.

Farrington, D.P., and B.C. Welsh. 2002. Improved street lighting and crime prevention. Justice Quarterly 19 (2): 313-342. 
Fine, A., and B. Van Rooij. 2017. For whom does deterrence affect behavior? identifying key individual differences. Law and Human Behavior 41 (4): 354.

Garvin, E., C. Branas, S. Keddem, J. Sellman, and C. Cannuscio. 2013. More than just an eyesore: Local insights and solutions on vacant land and urban health. Journal of Urban Health 90 (3): 412-426.

Garvin, E.C., C.C. Cannuscio, and C.C. Branas. 2013. Greening vacant lots to reduce violent crime: A randomised controlled trial. Injury Prevention 19 (3): 198-203.

Goodman, J.K., C.E. Cryder, and A. Cheema. 2013. Data collection in a flat world: The strengths and weaknesses of Mechanical Turk samples. Journal of Behavioral Decision Making 26 (3): 213-224.

Gregory, K. 2013. City to fit all streetlights with energy-saving led bulbs. https://www.nytimes.com/2013/ 10/25/nyregion/city-to-fit-all-streetlights-with-energy-saving-ledbulbs.html.

Groff, E.R., B. Kearley, H. Fogg, P. Beatty, H. Couture, and J. Wartell. 2005. A randomized experimental study of sharing crime data with citizens: Do maps produce more fear? Journal of Experimental Criminology 1 (1): 87-115.

Guha, B., and A.S. Guha. 2012. Crime and moral hazard: Does more policing necessarily induce private negligence? Economics Letters 115 (3): 455-459.

Gutierrez, C.M., and D.S. Kirk. 2017. Silence speaks: The relationship between immigration and the underreporting of crime. Crime \& Delinquency 63 (8): 926-950.

Haans, A., and Y.A. De Kort. 2012. Light distribution in dynamic street lighting: Two experimental studies on its effects on perceived safety, prospect, concealment, and escape. Journal of Environmental Psychology 32 (4): 342-352.

Hanslmaier, M. 2013. Crime, fear and subjective well-being: How victimization and street crime affect fear and life satisfaction. European Journal of Criminology 10 (5): 515-533.

Harbridge, L., and N. Malhotra. 2011. Electoral incentives and partisan conflict in Congress: Evidence from survey experiments. American Journal of Political Science 55 (3): 494-510.

Headley, A. M., K.-L. Blount-Hill, and V. J. S. John. 2020. The psychology of justice buildings: A survey experiment on police architecture, public sentiment, and race. Journal of Criminal Justice, 101747.

Heaton, P., P. Hunt, J. MacDonald, and J. Saunders. 2016. The short-and long-run effects of private law enforcement: Evidence from university police. The Journal of Law and Economics 59 (4): 889-912.

Herbert, D., and N. Davidson. 1994. Modifying the built environment: The impact of improved street lighting. Geoforum 25 (3): 339-350.

Herzog, S. 2003. Does the ethnicity of offenders in crime scenarios affect public perceptions of crime seriousness? A randomized survey experiment in Israel. Social Forces 82 (2): 757-781.

Imbens, G.W. 2010. Better LATE than nothing: Some comments on Deaton (2009) and Heckman and Urzua (2009). Journal of Economic Literature 48 (2): 399-423.

Jacobs, J. (1961). The death and life of great american cities.

Jeffords, C.R. 1983. The situational relationship between age and the fear of crime. The International Journal of Aging and Human Development 17 (2): 103-111.

Johnson, S.L., B.S. Solomon, W.C. Shields, E.M. McDonald, L.B. McKenzie, and A.C. Gielen. 2009. Neighborhood violence and its association with mothers' health: assessing the relative importance of perceived safety and exposure to violence. Journal of Urban Health 86 (4): 538-550.

Kahneman, D. 2011. Thinking, fast and slow. New York: Macmillan.

Kaplan, J., S. Ling, and M. Cuellar. 2020. Public beliefs about the accuracy and importance of forensic evidence in the united states. Science \& Justice. 60: 263-272.

Kershaw, C., N. Chivite-Matthews, C. Thomas, and R. Aust. 2001. the 2001 British Crime Survey: First results, England and Wales. London: United Kingdom Home Office.

Kleck, G., J. Tark, and J.J. Bellows. 2006. What methods are most frequently used in research in criminology and criminal justice? Journal of Criminal Justice 34 (2): 147-152.

Kochel, T.R., and D. Weisburd. 2017. Assessing community consequences of implementing hot spots policing in residential areas: Findings from a randomized field trial. Journal of Experimental Criminology 13 (2): 143-170.

Kondo, M., B. Hohl, S. Han, and C. Branas. 2016. Effects of greening and community reuse of vacant lots on crime. Urban Studies 53 (15): 3279-3295.

Kroes, E. P. and R. J. Sheldon (1988). Stated preference methods: an introduction. Journal of Transport Economics and Policy, 11-25.

Kuziemko, I., M.I. Norton, E. Saez, and S. Stantcheva. 2015. How elastic are preferences for redistribution? evidence from randomized survey experiments. The American Economic Review 105 (4): 1478-1508. 
Lee, J.G., and D. Fisher. 2020. The influence of scope, frames, and extreme willingness to pay responses on cost of crime estimates. American Journal of Criminal Justice 45 (2): 236-272.

Liao, T.C.-L., H. Yang, S. Lee, K. Xu, P. Feng, and S. Bennett. 2016. Augmented criminality-How mobile augmented reality crime overlays affect people's sense of place. AoIR Selected Papers of Internet Research.

Liberatore, W. 2018. Town's smart street lights to pay for themselves in 6 years. https://www.govtech. com/fs/Clifton-Park-to-buy-streetlights-to-save-on-energy-costs.html.

Loomes, G. 2007. Valuing reductions in the risks of being a victim of crime: The 'willingness to pay' approach to valuing the 'intangible' consequences of crime. International Review of Victimology 14 (2): 237-251.

Lorenc, T., S. Clayton, D. Neary, M. Whitehead, M. Petticrew, H. Thomson, S. Cummins, A. Sowden, and A. Renton. 2012. Crime, fear of crime, environment, and mental health and wellbeing: Mapping review of theories and causal pathways. Health \& Place 18 (4): 757-765.

Ludwig, J., and P.J. Cook. 2001. The benefits of reducing gun violence: Evidence from contingentvaluation survey data. Journal of Risk and Uncertainty 22 (3): 207-226.

MacDonald, J., J. Fagan, and A. Geller. 2016. The effects of local police surges on crime and arrests in New York City. PLoS ONE 11 (6): e0157223.

MacDonald, J., J. Klick, and B. Grunwald. 2012. The effect of privately provided police services on crime: Evidence from a geographic regression discontinuity design. Journal of the Royal Statistical Society (Series A) 179: 831-46.

Maddox, T. 2016. How la is now saving $\$ 9 \mathrm{~m}$ a year with led streetlights and converting them into ev charging stations. https://www.techrepublic.com/article/how-la-is-now-saving-9m-a-year-withledstreetlights-and-converting-them-into-ev-charging-stations/.

Markvica, K., G. Richter, and G. Lenz. 2019. Impact of urban street lighting on road users' perception of public space and mobility behavior. Building and Environment 154: 32-43.

Mengel, F., E. Tsakas, and A. Vostroknutov. 2016. Past experience of uncertainty affects risk aversion. Experimental Economics 19 (1): 151-176.

Michel, C., K.M. Heide, and J.K. Cochran. 2015. Sociodemographic correlates of knowledge about elite deviance. American Journal of Criminal Justice 40 (3): 639-660.

Moyer, R., J.M. MacDonald, G. Ridgeway, and C.C. Branas. 2019. Effect of remediating blighted vacant land on shootings: A citywide cluster randomized trial. American Journal of Public Health 109 (1): 140-144.

Mullinix, K.J., T.J. Leeper, J.N. Druckman, and J. Freese. 2015. The generalizability of survey experiments. Journal of Experimental Political Science 2 (2): 109-138.

Nagin, D.S., et al. 2013. Deterrence: A review of the evidence by a criminologist for economists. Annual Review of Economics 5 (1): 83-105.

Nagin, D.S., A.R. Piquero, E.S. Scott, and L. Steinberg. 2006. Public preferences for rehabilitation versus incarceration of juvenile offenders: Evidence from a contingent valuation survey. Criminology \& Public Policy 5 (4): 627-651.

Nagin, D.S., and R.J. Sampson. 2019. The real gold standard: Measuring counterfactual worlds that matter most to social science and policy. Annual Review of Criminology 2: 123-145.

Ozkan, T. 2019. Criminology in the age of data explosion: New directions. The Social Science Journal 56 (2): 208-219.

Pain, R., R. MacFarlane, K. Turner, and S. Gill. 2006. 'when, where, if, and but': Qualifying gis and the effect of streetlighting on crime and fear. Environment and Planning A 38 (11): 2055-2074.

Painter, K. 1994. The impact of street lighting on crime, fear, and pedestrian street use. Security Journal 5 (3): 116-124.

Painter, K. 1996. The influence of street lighting improvements on crime, fear and pedestrian street use, after dark. Landscape and Urban Planning 35 (2-3): 193-201.

Painter, K., and D.P. Farrington. 1999. Improved street lighting: Crime reducing effects and costbenefit analyses. Security Journal 12 (4): 17-32.

Painter, K., and D.P. Farrington. 1999. Street lighting and crime: diffusion of benefits in the Stokeon Trent project. Surveillance of public space: CCTV, street lighting and crime prevention 10: 77-122.

Patch, C.M., C.G. Roman, T.L. Conway, R.B. Taylor, K.A. Gavand, B.E. Saelens, M.A. Adams, K.L. Cain, J.K. Engelberg, L. Mayes, et al. 2019. Crime and physical activity: development of a conceptual framework and measures. Journal of Physical Activity and Health 16 (10): 818-829. 
Piquero, A.R., and L. Steinberg. 2010. Public preferences for rehabilitation versus incarceration of juvenile offenders. Journal of Criminal Justice 38 (1): 1-6.

Piza, E.L., J.M. Caplan, L.W. Kennedy, and A.M. Gilchrist. 2015. The effects of merging proactive cctv monitoring with directed police patrol: A randomized controlled trial. Journal of Experimental Criminology 11 (1): 43-69.

Pogarsky, G., K. Kim, and R. Paternoster. 2005. Perceptual change in the National Youth Survey: Lessons for deterrence theory and offender decision-making. Justice Quarterly 22 (1): 1-29.

Quillian, L., and D. Pager. 2001. Black neighbors, higher crime? The role of racial stereotypes in evaluations of neighborhood crime. American Journal of Sociology 107 (3): 717-767.

Ratcliffe, J.H., E.R. Groff, E.T. Sorg, and C.P. Haberman. 2015. Citizens' reactions to hot spots policing: Impacts on perceptions of crime, disorder, safety and police. Journal of Experimental Criminology 11 (3): 393-417.

Ridgeway, G., J. Grogger, R.A. Moyer, and J.M. Macdonald. 2019. Effect of gang injunctions on crime: A study of Los Angeles from 1988-2014. Journal of Quantitative Criminology 35 (3): 517-541.

Robinson, M.B. 2013. The theoretical development of "CPTED": Twenty-five years of responses to C. Ray Jeffery. The Criminology of Criminal Law 8: 427-462.

Roman, C.G., and A. Chalfin. 2008. Fear of walking outdoors: A multilevel ecologic analysis of crime and disorder. American Journal of Preventive Medicine 34 (4): 306-312.

Roman, C.G., C.R. Knight, A. Chalfin, and S.J. Popkin. 2009. The relation of the perceived environment to fear, physical activity, and health in public housing developments: Evidence from Chicago. Journal of Public Health Policy 30 (1): S286-S308.

Roman, J., T. Dunworth, and K. Marsh. 2010. Cost-benefit analysis and crime control. Washington DC: Urban Institute Press.

Rosenbaum, D.P. 2006. The limits of hot spots policing. Police innovation: Contrasting perspectives, $245-263$.

Rothman, A.J., W.M. Klein, and N.D. Weinstein. 1996. Absolute and relative biases in estimations of personal risk 1. Journal of Applied Social Psychology 26 (14): 1213-1236.

Sampson, R.J., S.W. Raudenbush, and F. Earls. 1997. Neighborhoods and violent crime: A multilevel study of collective efficacy. Science 277 (5328): 918-924.

Samuels, D., and C. Zucco Jr. 2014. The power of partisanship in Brazil: Evidence from survey experiments. American Journal of Political Science 58 (1): 212-225.

Samuelson, P. A. (1954). The pure theory of public expenditure. The Review of Economics and Statistics, 387-389.

Schivelbusch, W. 1987. The policing of street lighting. Yale French Studies 73: 61-74.

Sherman, L.W., P.R. Gartin, and M.E. Buerger. 1989. Hot spots of predatory crime: Routine activities and the criminology of place. Criminology 27 (1): 27-56.

Sherman, L.W., and D. Weisburd. 1995. General deterrent effects of police patrol in crime "hot spots": A randomized, controlled trial. Justice Quarterly 12 (4): 625-648.

Shi, L. 2020. Are public misperceptions of crime trends a cause of criminality? Evidence from a randomized experiment. Journal of Crime and Justice 43 (1): 49-64.

Shinew, K.J., M. Stodolska, C.G. Roman, and J. Yahner. 2013. Crime, physical activity and outdoor recreation among Latino adolescents in Chicago. Preventive Medicine 57 (5): 541-544.

Shueh, J. 2017. Chicago is spending \$160 million on smart street lights. https://statescoop.com/chicagoisspending-160-million-on-smart-street-lights/.

Skogan, W. G. (1990). Disorder and decline: Crime and the spiral of decay in american cities.

Slovic, P., B. Fischhoff, and S. Lichtenstein. 1982. Why study risk perception? Risk Analysis 2 (2): 83-93.

Stanko, E.A. 1995. Women, crime, and fear. The Annals of the American Academy of Political and Social Science 539 (1): 46-58.

Steinbach, R., C. Perkins, L. Tompson, S. Johnson, B. Armstrong, J. Green, C. Grundy, P. Wilkinson, and P. Edwards. 2015. The effect of reduced street lighting on road casualties and crime in England and Wales: controlled interrupted time series analysis. Journal of Epidemiology and Community Health 69 (11): 1118-1124.

Stickle, B.F. 2015. Examining public willingness-to-pay for burglary prevention. Crime Prevention and Community Safety 17 (2): 120-138.

Stodolska, M., K.J. Shinew, J.C. Acevedo, and C.G. Roman. 2013. "I was born in the hood": Fear of crime, outdoor recreation and physical activity among Mexican-american urban adolescents. Leisure Sciences 35 (1): 1-15. 
Struyf, P. 2020. Fear of the dark. In Crime and fear in public places, ed. V. Ceccato and M.K. Nalla, 347. Abington: Routledge.

Thaler, R.H., and C.R. Sunstein. 2009. Nudge: Improving decisions about health, wealth, and happiness. New York: Penguin.

Ticknor, B., and S. Tillinghast. 2011. Virtual reality and the criminal justice system: New possibilities for research, training, and rehabilitation. Journal For Virtual Worlds Research. https://doi.org/10. 4101/jvwr.v4i2.2071.

Tien, J. M., V. F. O'Donnell, A. Barnett, and P. Mirchandane. 1977. Street Lighting Projects: National Evaluation Program, Phase I Final Report. Public Systems Evaluation.

Trickey, E. 2017. Chicago is spending \$160 million on smart street lights. The Detroit Success Story Visible From Space.

Van Gelder, J.-L., R.E. De Vries, A. Demetriou, I. Van Sintemaartensdijk, and T. Donker. 2019. The virtual reality scenario method: Moving from imagination to immersion in criminal decision-making research. Journal of research in crime and delinquency 56 (3): 451-480.

Van Gelder, J.-L., C. Nee, M. Otte, A. Demetriou, I. Van Sintemaartensdijk, and J.-W. Van Prooijen. 2017. Virtual burglary: Exploring the potential of virtual reality to study burglary in action. Journal of Research in Crime and Delinquency 54 (1): 29-62.

Van Gelder, J.-L., M. Otte, and E.C. Luciano. 2014. Using virtual reality in criminological research. Crime Science 3 (1): 10.

Vollaard, B., and J.C. Van Ours. 2011. Does regulation of built-in security reduce crime? Evidence from a natural experiment. The Economic Journal 121 (552): 485-504.

Vrij, A., and F.W. Winkel. 1991. Characteristics of the built environment and fear of crime: A research note on interventions in unsafe locations. Deviant Behavior 12 (2): 203-215.

Weichselbaum, S. and N. Lewis. 2020. Support for defunding the police department is growing. Here's why it's not a silver bullet. The Marshall Project.

Weisburd, D., and L. Green. 1995. Policing drug hot spots: The Jersey City drug market analysis experiment. Justice Quarterly 12 (4): 711-735.

Weisburd, D., E.R. Groff, and S.-M. Yang. 2014. Understanding and controlling hot spots of crime: The importance of formal and informal social controls. Prevention Science 15 (1): 31-43.

Weisburd, D., J.C. Hinkle, C. Famega, and J. Ready. 2011. The possible "backfire" effects of hot spots policing: An experimental assessment of impacts on legitimacy, fear and collective efficacy. Journal of Experimental Criminology 7 (4): 297-320.

Weisburd, D., N.A. Morris, and E.R. Groff. 2009. Hot spots of juvenile crime: A longitudinal study of arrest incidents at street segments in Seattle, Washington. Journal of Quantitative Criminology 25 (4): 443 .

Weisburd, S. 2016. Police presence, rapid response rates, and crime prevention. The Review of Economics and Statistics, 1-45.

Weisel, D.L. 2002. Burglary of single-family houses. Washington, DC: US Department of Justice Office of Community Oriented Policing Services.

Welsh, B.C., and D.P. Farrington. 2008. Effects of improved street lighting on crime. Campbell Systematic Reviews 4 (1): 1-51.

Willis, K.G., N.A. Powe, and G.D. Garrod. 2005. Estimating the value of improved street lighting: A factor analytical discrete choice approach. Urban Studies 42 (12): 2289-2303.

Publisher's Note Springer Nature remains neutral with regard to jurisdictional claims in published maps and institutional affiliations. 